\title{
BMJ Open Longitudinal study of patients with chronic Chagas cardiomyopathy in Brazil (SaMi-Trop project): a cohort profile
}

\author{
Clareci Silva Cardoso, ${ }^{1,2}$ Ester Cerdeira Sabino, ${ }^{3}$ Claudia Di Lorenzo Oliveira, ${ }^{1}$ \\ Lea Campos de Oliveira, ${ }_{4}^{4}$ Ariela Mota Ferreira, ${ }^{5}$ Edécio Cunha-Neto, $, 6,7,8$ \\ Ana Luiza Bierrenbach, ${ }^{3}$ João Eduardo Ferreira, ${ }^{9}$ Desirée Sant'Ana Haikal, ${ }^{5}$ \\ Arthur L Reingold, ${ }^{2}$ Antonio Luiz P Ribeiro ${ }^{10}$
}

To cite: Cardoso CS, Sabino EC, Oliveira CDL, et al. Longitudinal study of patients with chronic Chagas cardiomyopathy in Brazil (SaMi-Trop project): a cohort profile. BMJ Open 2016;6: e011181. doi:10.1136/ bmjopen-2016-011181

- Prepublication history for this paper is available online. To view these files please visit the journal online (http://dx.doi.org/10.1136/ bmjopen-2016-011181).

Received 20 January 2016 Revised 17 March 2016 Accepted 29 March 2016

CrossMark

For numbered affiliations see end of article.

Correspondence to Professor Clareci Silva Cardoso; clarecicardoso@ yahoo.com.br

\section{ABSTRACT}

Purpose: We have established a prospective cohort of 1959 patients with chronic Chagas cardiomyopathy to evaluate if a clinical prediction rule based on ECG, brain natriuretic peptide (BNP) levels, and other biomarkers can be useful in clinical practice. This paper outlines the study and baseline characteristics of the participants.

Participants: The study is being conducted in 21 municipalities of the northern part of Minas Gerais State in Brazil, and includes a follow-up of 2 years. The baseline evaluation included collection of sociodemographic information, social determinants of health, health-related behaviours, comorbidities, medicines in use, history of previous treatment for Chagas disease, functional class, quality of life, blood sample collection, and ECG. Patients were mostly female, aged 50-74 years, with low family income and educational level, with known Chagas disease for $>10$ years; $46 \%$ presented with functional class $>I I$. Previous use of benznidazole was reported by $25.2 \%$ and permanent use of pacemaker by $6.2 \%$. Almost half of the patients presented with high blood cholesterol and hypertension, and one-third of them had diabetes mellitus. N-terminal of the prohormone BNP (NTProBNP) level was $>300 \mathrm{pg} / \mathrm{mL}$ in $30 \%$ of the sample.

Findings to date: Clinical and laboratory markers predictive of severe and progressive Chagas disease were identified as high NT-ProBNP levels, as well as symptoms of advanced heart failure. These results confirm the important residual morbidity of Chagas disease in the remote areas, thus supporting political decisions that should prioritise in addition to epidemiological surveillance the medical treatment of chronic Chagas cardiomyopathy in the coming years. The São Paulo-Minas Gerais Tropical Medicine Research Center (SaMi-Trop) represents a major challenge for focused research in neglected diseases, with knowledge that can be applied in primary healthcare.

Future plans: We will continue following this patients' cohort to provide relevant information about the development and progression of Chagas disease in remotes areas, with social and economic inequalities. Trial registration number: NCT02646943; Pre-results.

\section{Strengths and limitations of this study}

- In this large multicentre cohort of patients with Chagas cardiomyopathy previous use of benznidazole was reported by one quarter of the patients.

- Clinical and laboratory markers predictive of severe and progressive Chagas disease (ChD) were identified in the São Paulo-Minas Gerais Tropical Medicine Research Center (SaMi-Trop) cohort, as high N-terminal of the prohormone BNP (NT-ProBNP) levels, as well as symptoms of advanced heart failure.

- Results presented in this paper confirm the important residual morbidity of $\mathrm{ChD}$ in remote areas, thus supporting political decisions that should prioritise in addition to epidemiological surveillance the medical treatment of CCC in the coming years.

- The SaMi-Trop cohort represents a major challenge for focused research in neglected diseases, with knowledge that can be applied in primary health care.

- One weakness is the lack of baseline echocardiograms, which could help in the clinical stratification of patients. However, this information is being collected in the second follow-up visit.

\section{INTRODUCTION}

Chagas disease, which is caused by the protozoan parasite Trypanosoma cruzi, remains one of the most neglected diseases in the world, with 8-10 million infected people. The most important consequence of Chagas disease is chronic Chagas cardiomyopathy, which occurs in $20-40 \%$ of infected persons, ${ }^{1-4}$ with an incidence rate of $1.85 \%$ person-year. ${ }^{4}$

Chronic Chagas cardiomyopathy comprises a wide range of manifestations, including heart failure, arrhythmias, heart blocks, sudden death, thromboembolism, and 
stroke. $^{5}$ Clinical presentation typically varies widely according to the degree of myocardial damage, and most patients present a mild form of heart disease frequently characterised only by the presence of asymptomatic abnormalities on the ECG or in other complimentary examinations. ${ }^{6}$ The Brazilian Consensus of Chagas disease defines Chagas cardiomyopathy as the presence of typical ECG abnormalities in patients with a positive serological test for T. cruzi infection. ${ }^{7}$ When heart failure and/or severe arrhythmias manifest, the prognosis is ominous, with high and premature mortality rates in adult male patients, ${ }^{8}$ as well as in the elderly. ${ }^{9}$ Indeed, when compared with patients with idiopathic cardiomyopathy, patients with chronic Chagas cardiomyopathy have poorer survival, irrespective of other clinical and echocardiographic parameters. ${ }^{10}$

Chronic Chagas cardiomyopathy is a potentially lethal condition, but the severity of the disease varies widely and accurate stratification of the risk of disease progression and death remains an unsolved challenge. ${ }^{5}$ Risk scores have been developed, ${ }^{11-13}$ including a validated one. ${ }^{11}$ However, current risk scores rely on the availability of several diagnostic tests, including Holter monitoring, stress testing, echocardiographic examination and chest X-ray, ${ }^{11}$ or special examinations such as signal averaged ECG. ${ }^{12} 13$ These methods are not readily available in the rural endemic areas and have a limited role in risk stratification in the primary care setting. Indeed, a simple, low-cost and easy-to-use prognostic model suitable for the primary care setting is lacking. Although some promising studies show the potential value of some new biomarkers, ${ }^{14}{ }^{15}$ the lack of validated and easily available biomarkers for active infection or clinical end points are a problem for assessing the performance of new drugs or therapeutic interventions. In addition, given the lack of a health service structure, mainly in remote areas, along with the low levels of awareness among healthcare providers, cases of chronic Chagas cardiomyopathy are under-recognised and undertreated.

Seeking to contribute to the knowledge of Chagas disease, a large cohort of patients with chronic Chagas cardiomyopathy was established in Minas Gerais State (Brazil). This cohort aims to develop a prognostic algorithm-based on simple ECG measurements in conjunction with clinical information and brain natriuretic peptide (BNP) levels-that would be used to predict the risk of disease progression and death in patients with chronic Chagas cardiomyopathy and be useful in the clinical management of such patients. This paper outlines the study and baseline characteristics of the cohort participants.

\section{COHORT DESCRIPTION}

The São Paulo-Minas Gerais Tropical Medicine Research Center (SaMi-Trop) consists of a network of collaborating scientists in the States of Minas Gerais and São Paulo which has been established for the purpose of developing and conducting research projects on Chagas disease. The SaMi-Trop project is a prospective cohort study with at least 2 years of follow-up, including one visit at baseline and another at 24 months. The cohort of patients with chronic Chagas cardiomyopathy was established by using patients under the care of the Telehealth Network of Minas Gerais, a programme designed to support primary care in Minas Gerais State, Brazil. ${ }^{16}$ In this programme, all patients' ECG and clinical data are sent to a central reading unit centre that also collects clinical data such as the history of Chagas disease. Using this database, we selected 21 municipalities within a limited region in the northern part of the State of Minas Gerais where the prevalence of patients with chronic Chagas cardiomyopathy was expected to be high (figure 1).

Eligible patients were selected based on the ECG results performed in 2011-2012 by the Telehealth Network, which from now on will be called index ECG. Only patients who fulfilled all of the following inclusion criteria were selected: (1) self-reported Chagas disease; (2) presence of the following abnormalities on the index ECG: ${ }^{17}$ possible old myocardial infarction (major $\mathrm{Q}$ wave abnormalities or minor $\mathrm{Q}$ waves abnormalities with ST segment or $\mathrm{T}$ wave abnormalities), complete intraventricular block (right, left or unspecified), frequent supraventricular or ventricular premature beats, major isolated ST segment or $\mathrm{T}$ wave abnormalities, atrial fibrillation or flutter or supraventricular tachycardia or other major arrhythmias, major atrioventricular conduction abnormalities or pacemaker use, or major QT prolongation (QT index $>115 \%$ ), left or right ventricular hypertrophy and (3) aged 19 years or more. The exclusion criteria included pregnancy or breast feeding, and any life-threatening disease with an ominous prognosis that suggested a life expectancy of $<2$ years.

The simple size was calculated considering the minimal number of events per variable acceptable in a proportional hazards regression analysis of 10 events per variable. ${ }^{18}$ As the prediction model has to be developed and validated, and the whole sample will be divided into two, the number of events should be 200. For a 2-year follow-up period and annual mortality rate of $5 \%$ in chronic Chagas cardiomyopathy ( $10 \%$ in 2 years), the calculated sample size was 2000 participants.

All eligible participants were tested for the presence of anti- $T$. cruzi antibodies using chemiluminescent microparticle immunoassay. Negative results were confirmed by two other enzyme immunoassay (EIA) presenting different antigens. The final cohort consists of patients confirmed to be seropositive. The patients' distribution by municipalities and the distance from the reference centre in health is presented in table 1.

The cohort will be followed for 2 years, until primary outcome or loss to follow-up. The primary outcome is death and the secondary outcomes are changes in the ECG pattern and hospitalisation due to cardiovascular complications. Ascertainment of the occurrence of deaths will be done using the National Mortality Information System (SIM) from the Ministry of Health. 
Figure 1 Geographical location of the 21 municipalities included in the São Paulo-Minas Gerais Tropical Medicine Research Center (SaMi-Trop) project. Minas Gerais, Brazil.

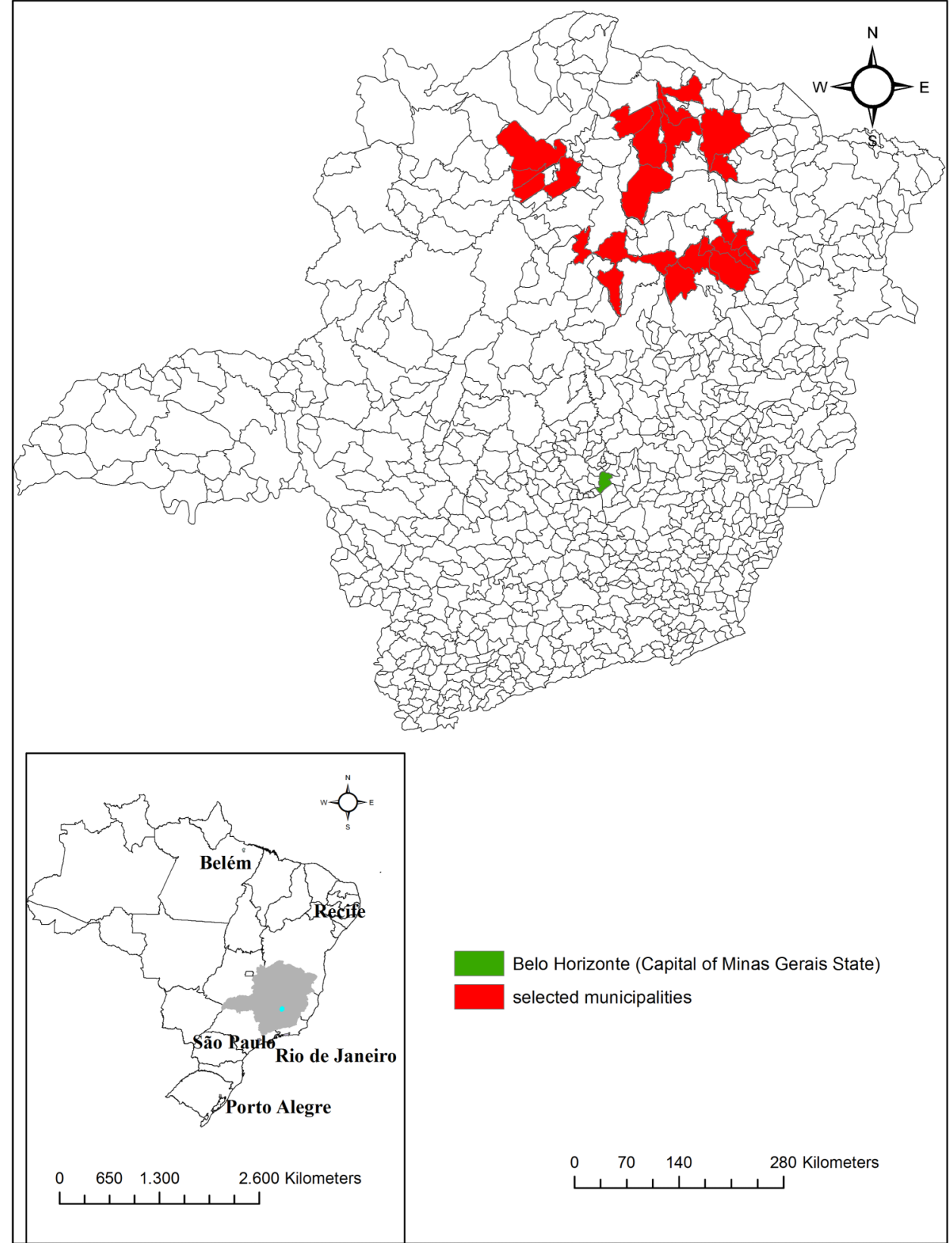

Table 2 summarises the types of data collected at baseline and of those that will be collected at the 2-year follow-up visit. All eligible participants were recruited by the family health programme team. The baseline visit was performed at public health primary care units by previously trained staff. The patients were interviewed using a standardised questionnaire, and had a blood sample collected and an ECG evaluation. The data were collected electronically and sent to the data centre at the University of São Paulo via a webbased system.

A resting 12-lead ECG was recorded using an ECG PC machine (TEB, São Paulo, Brazil). The ECG recordings were sent electronically to the Telehealth system and read by a trained cardiologist; the written report was subsequently returned to the patient's physician. For research purposes, ECGs were also automatically analysed using the University of Glasgow ECG analysis programme (release 28.5, issued on January 2014) and reviewed by trained cardiologists to ensure quality control. ECGs will be classified using the Minnesota Code criteria using variables derived from the median complex of the Glasgow University software measurement matrix. ${ }^{22}$

Blood was collected into serum-separating tubes, and allowed to clot at room temperature for $30 \mathrm{~min}$. The serum was centrifuged at $1300 \mathrm{~g}$ for $10 \mathrm{~min}$ at room temperature. This was then subjected to storage at $-20^{\circ} \mathrm{C}$ and later shipped with dry ice to the central laboratory in São Paulo.

Brazilian Mortality Information (SIM) data will be used to ascertain patients' vital status after the follow-up period as well as the underlying causes of death, which are coded under the International Classification of Disease, 10th Revision (ICD-10). 
Table 1 Distribution of patients including in São

Paulo-Minas Gerais Tropical Medicine Research Center

(SaMi-Trop) cohort according to the municipality and distance to the reference centre, Montes Claros $(n=1959)$

\begin{tabular}{lccc}
\hline Municipalities & Number & Per cent & Distance (km) \\
\hline São Francisco & 325 & 16.6 & 163 \\
Carbonita & 202 & 10.3 & 203 \\
Minas Novas & 164 & 8.4 & 289 \\
Janaúba & 166 & 8.5 & 134 \\
Turmalina & 131 & 6.7 & 264 \\
Bocaiúva & 128 & 6.5 & 47 \\
Chapada do Norte & 122 & 6.2 & 295 \\
Berilo & 113 & 5.8 & 333 \\
Porteirinha & 71 & 3.6 & 170 \\
Brasília de Minas & 71 & 3.6 & 105 \\
Fruta de Leite & 68 & 3.5 & 186 \\
Claro dos Poções & 62 & 3.2 & 79.5 \\
Verdelândia & 69 & 3.5 & 173 \\
Pai Pedro & 56 & 2.9 & 185 \\
Ubaí & 54 & 2.8 & 153 \\
Leme do Prado & 42 & 2.1 & 273 \\
Francisco Sá & 38 & 1.9 & 52 \\
Rio Pardo de Minas & 28 & 1.4 & 276 \\
Jenipapo de Minas & 19 & 1.0 & 369 \\
Francisco Badaró & 16 & 0.8 & 347 \\
Monte Azul & 14 & 0.7 & 244 \\
Total & 1959 & 100.0 & - \\
\hline
\end{tabular}

In this paper, a descriptive analysis of the baseline characteristics of the cohort participants was done using frequency and percentage distribution. SPSS V.19 (SPSS Inc, IBM, Armonk, New York, USA) and ArcView, V.10.1 (Environmental Systems Research Institute Inc, http:// www.esri.com/software/arcview/) were used.

This cohort study is a component of a larger study to evaluate biomarkers of Chagas disease sponsored by a grant from National Institute of Allergy and Infectious Diseases (NIAID)/National Institutes of Health (NIH) Neglected Tropical Disease Centre.

\section{CHARACTERISTICS OF THE STUDY POPULATION}

Of the 55480 ECGs performed in the 21 selected municipalities from 2011 to 2012, a total of 4689 patients were eligible for the study, and 2157 were located and completed the baseline assessment in 2013-2014. In comparison to the eligible group, the participants had a higher percentage of women $(67.1 \%$ vs $59.9 \%, \mathrm{p}<0.01)$ and were younger ( 59.5 vs 60.7 years, $\mathrm{p}<0.01$ ). The final cohort consists of $1959(90.8 \%)$ participants confirmed to be seropositive for Chagas disease (figure 2).

Table 3 shows the main sociodemographic characteristics, socioeconomic categories and self-perception of health of study participants at baseline. Most patients were female $(67.5 \%)$, aged between 50 and 74 years $(62.6 \%)$, sharing the same household with two other people or less $(56.6 \%)$, and had a family monthly income of US\$327. The educational level was very low
Table 2 Measurements obtained at different phases of the SaMi-Trop study

\begin{tabular}{|c|c|}
\hline Phase & Measurements \\
\hline $\begin{array}{l}\text { Baseline: 2013- } \\
2014\end{array}$ & $\begin{array}{l}\text { Questionnaires with sociodemographic } \\
\text { information, social determinants of } \\
\text { health, health-related behaviours } \\
\text { (smoking, alcohol consumption and } \\
\text { physical activity), self-reported } \\
\text { comorbidities, medication use, history of } \\
\text { previous treatment for Chagas disease, } \\
\text { signs and symptoms, functional class } \\
\text { (Cardiovascular Functional Class } \\
\text { Scale) }{ }^{19} \text { and quality of life } \\
\text { (WHO-QOL-BREF) } \\
\text { ECG } \\
\text { Blood collection: immunoassays, PCR } \\
\text { for } T \text {. cruzi, NT-ProBNP }\end{array}$ \\
\hline $\begin{array}{l}\text { Follow-up: } \\
\text { 2015-2016 }\end{array}$ & 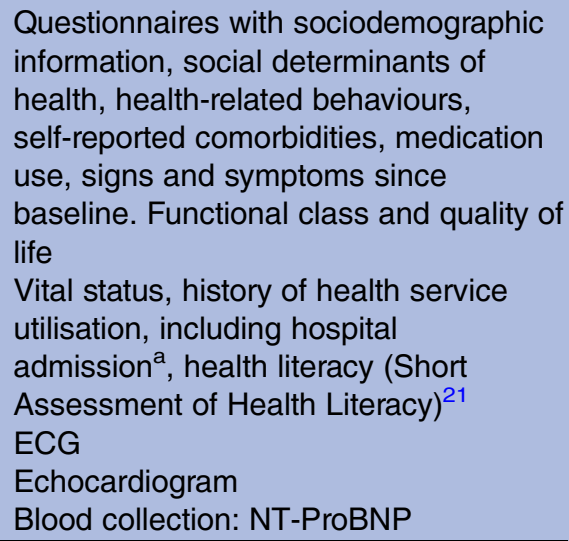 \\
\hline
\end{tabular}

NT-ProBNP, N-terminal of the prohormone brain natriuretic peptide; SaMi-Trop, São Paulo-Minas Gerais Tropical Medicine Research Center; T. cruzi, Trypanosoma cruzi; WHO-QOL-BREF, WHO Quality of Life-BREF.

with $38.7 \%$ having had between 1 and 4 years of school, and $34.4 \%$ never having attended school. Cohort members self-reported their health status as average $(57.7 \%)$ or good $(25.8 \%)$.

The majority of the patients self-reported that they have had Chagas disease for over 10 years, and that they had at least one family member with a history of Chagas disease. Based on the New York Heart Association (NYHA) Functional Classification, $45.9 \%$ of the patients were classified as level II or more (ie, have symptoms of heart failure). Among Chagas disease patients in the cohort, $6.2 \%$ reported permanent use of a pacemaker. Previous treatment for Chagas disease was reported by $51.6 \%$ of Chagas disease patients $(25.2 \%)$, including 492 who reported previous treatment with benznidazole. The N-terminal of the prohormone BNP (NT-ProBNP) level was $>300 \mathrm{pg} / \mathrm{mL}$ in $30 \%$ of the sample (table 4 ).

As seen in table 5 , the prevalence of one or more selfreported comorbid conditions at baseline was high, including high serum cholesterol $(40.1 \%)$, hypertension $(36.0 \%)$, diabetes mellitus $(10.1 \%)$, thyroid disorder $(8.1 \%)$, and kidney disease $(7.3 \%)$. Leishmaniasis was reported by 22 patients $(1.2 \%)$. Only $22.3 \%$ of patients 


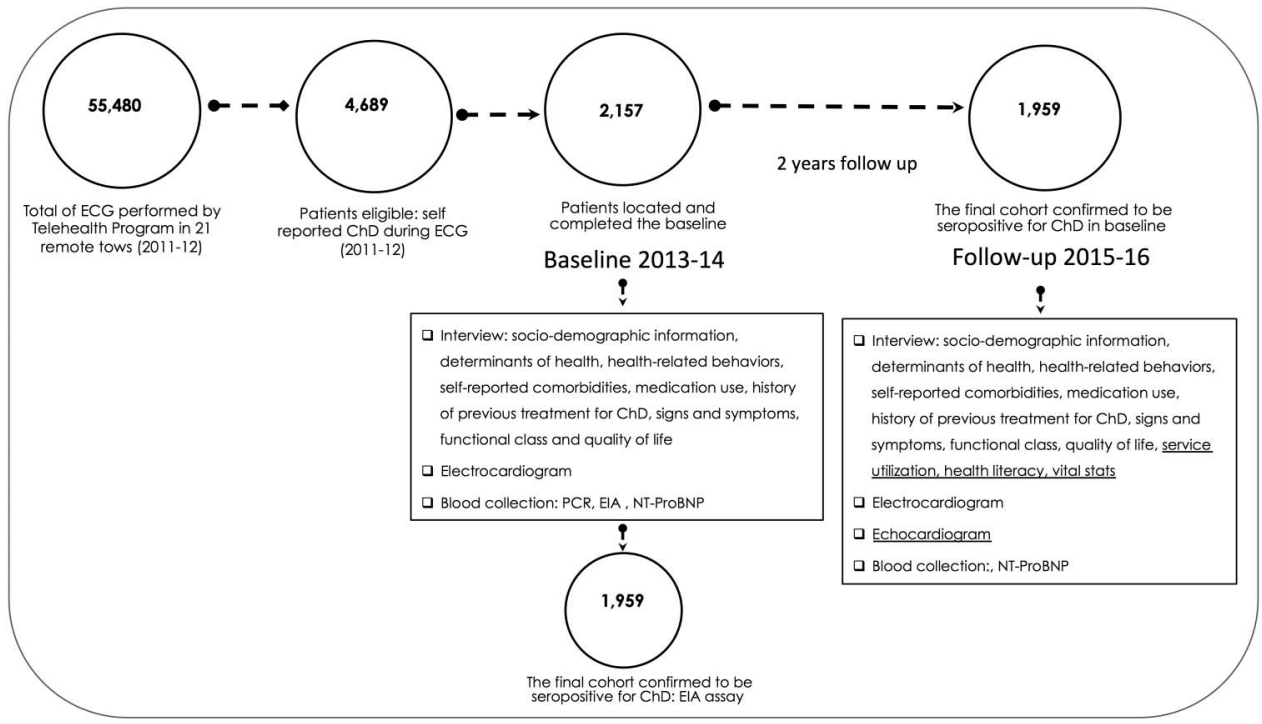

Figure 2 The SaMi-Trop project diagram. ChD, Chagas disease; EIA, enzyme immunoassay; NT-ProBNP, N-terminal of the prohormone brain natriuretic peptide; SaMi-Trop, São Paulo-Minas Gerais Tropical Medicine Research Center.

reported having performed any physical activity during the prior week, $16.2 \%$ reported having drunk alcohol in the previous month, and $7.3 \%$ reported that they were current smokers. In terms of medications, $36.4 \%$ of patients reported the current use of one or two medicines, while $30.1 \%$ reported no current use of any medication. The most common medicines being used were diuretics $(49.1 \%)$, ACE (28.6\%), angiotensin receptor blockers (ARBs) $(28.4 \%)$, aspirin (26.2\%), and amiodarone (22\%).

Considering the fact that almost half of the patients were in functional class II or more, with $30 \%$ with BNP levels higher than 300 units/L, there is an overall low usage of the recommended drugs for heart failure, particularly of $\beta$-blockers. This may explain at least in part the high frequency of cardiac symptoms reported: $63.5 \%$ had racing heartbeat, $62.5 \%$ had prolonged fainting spells or dizziness, $61.3 \%$ had an abnormal ECG, $61.0 \%$ had heart palpitations, and $59.4 \%$ had shortness of breath at exercises. The relative high frequency of amiodarone use may be related to the high frequency of cardiac arrhythmias in chronic Chagas cardiomyopathy, as well as the established practice, in Brazil, to prescribe amiodarone to prevent sudden death.

\section{FINDINGS TO DATE}

Clinical and laboratory markers predictive of severe and progressive Chagas disease were identified in SaMi-Trop cohort, as high NT-ProBNP levels, as well as symptoms of advanced heart failure. The NT-ProBNP level was $>300 \mathrm{pg} / \mathrm{mL}$ in $30 \%$ of the sample. High circulating levels of natriuretic peptides are related to the presence of left ventricular dysfunction ${ }^{23}$ and a higher risk of death. ${ }^{24}$

Among Chagas disease patients in the cohort, 6.2\% reported permanent use of a pacemaker. This percentage is far below the $14.0 \%$ found in another recently published Brazilian cohort study of patients with Chagas disease. ${ }^{25}$ However, Chagas disease is still a major cause of use of pacemakers and defibrillators in Brazil, surpassing the indications due to coronary artery disease in some regions. The literature too point out the underuse of this device in Brazil when compared with other countries, ${ }^{26}$ which is unfortunately what we expected to find in the remote regions represented in the current study.

In this large multicentre cohort, previous use of benznidazole was reported by one-fourth of the patients. It is well known that the persistence of $T$. cruzi is directly related in the pathology of the chronic phase, but it remains to be proved that parasite load reduction by trypanocidal treatment leads to concomitant attenuation of cardiomyopathy. ${ }^{25}$ In the recently released BENEFIT trial, ${ }^{25}$ that included Brazilian patients, treatment with benznidazole did not significantly reduce cardiac clinical deterioration in the 5 years of follow-up in Chagas cardiomyopathy.

Although T. cruzi infection does not have a sexual predilection, ${ }^{27}$ studies show higher prevalence among women. ${ }^{28}{ }^{29}$ This difference may be related to frequent use of health services by women, even after controlling for restrictions in routine activities due to health reasons ${ }^{30}$ as well as greater availability to participate in scientific studies, especially those with a longitudinal component such as in this investigation.

Results presented in this paper confirm the important residual morbidity of Chagas disease in the remote areas, thus supporting political decisions that should prioritise in addition to conducting epidemiological surveillance of the medical treatment for chronic Chagas cardiomyopathy in the coming years. The SaMi-Trop cohort represents a major challenge for focused research in neglected diseases, with knowledge that can be applied in primary healthcare. The study has the potential to provide relevant information about the development and progression of Chagas disease in remote areas with social and economic inequalities. 
Table 3 Sociodemographic characteristics of SaMi-Trop cohort members $(n=1959)$

\begin{tabular}{|c|c|c|}
\hline Variables & $\mathbf{N}$ & Per cent \\
\hline \multicolumn{3}{|l|}{ Sex } \\
\hline Female & 1.323 & 67.5 \\
\hline Male & 636 & 32.5 \\
\hline \multicolumn{3}{|l|}{ Age } \\
\hline$<50$ years & 499 & 25.6 \\
\hline 50-74 years & 1.223 & 62.6 \\
\hline$>74$ years & 231 & 11.8 \\
\hline \multicolumn{3}{|l|}{ Number of household members } \\
\hline $1-3$ & 1.106 & 56.6 \\
\hline $4-6$ & 709 & 36.3 \\
\hline $7-17$ & 138 & 7.1 \\
\hline \multicolumn{3}{|l|}{ Family monthly income data } \\
\hline$>$ US $\$ 327$ & 1.037 & 53.1 \\
\hline$\leq \mathrm{US} \$ 327$ & 916 & 46.9 \\
\hline \multicolumn{3}{|l|}{ Skin colour } \\
\hline Mixed & 1.144 & 58.6 \\
\hline White & 426 & 21.8 \\
\hline Black & 348 & 17.8 \\
\hline Others & 32 & 1.8 \\
\hline \multicolumn{3}{|l|}{ Years of school } \\
\hline $1-4$ year & 862 & 44.2 \\
\hline Illiterate & 670 & 34.4 \\
\hline $5-8$ years & 320 & 16.4 \\
\hline Other & 98 & 5.0 \\
\hline \multicolumn{3}{|l|}{ Marital status } \\
\hline Married or living with partner & 1.238 & 63.4 \\
\hline Widower & 449 & 23.0 \\
\hline Single & 176 & 9.0 \\
\hline Divorced & 90 & 4.6 \\
\hline \multicolumn{3}{|l|}{ Self-perception of health } \\
\hline Very good & 57 & 2.9 \\
\hline Good & 499 & 25.8 \\
\hline Average & 1.116 & 57.7 \\
\hline Bad or very bad & 264 & 13.6 \\
\hline
\end{tabular}

Small differences in total $\mathrm{N}$ for each variable are due to missing values.

Others in Skin colours include Asians (27) and Native Americans (5).

Others in Educational level included: elementary school (81) and graduate school (17).

Dollar quotation from July 2013.

\section{STRENGTHS AND LIMITATIONS}

The SaMi-Trop is one of the largest multicentre cohort study of Chagas disease conducted in the world. It has the potential of identifying biomarkers that will be used to predict the risk of disease progression and death, as well as permit comparative analysis with other similar cohorts. Most studies that evaluated biomarkers in Chagas disease had a cross-sectional design. The large number of patients included in this investigation is outstanding, especially in a rural and dispersed area. Our preliminary results confirmed the important residual morbidity of Chagas disease in such remote areas and found that these patients are currently being undertreated. We hope that our findings will guide political decisions aiming at enhancing
Table 4 Distribution of patients according to self-reported Chagas disease, cardiovascular functional class and NT-ProBNP results in the SaMi-Trop study

\begin{tabular}{|c|c|c|c|}
\hline Variables & $\begin{array}{l}\text { Valid } \\
\mathbf{N}\end{array}$ & $\mathbf{N}$ & $\begin{array}{l}\text { Per } \\
\text { cent }\end{array}$ \\
\hline Chagas disease self-reported & 1.955 & & \\
\hline Yes & & 1870 & 95.6 \\
\hline No & & 64 & 3.3 \\
\hline No response & & 21 & 1.1 \\
\hline $\begin{array}{l}\text { Duration of Chagas disease } \\
\text { (years) }\end{array}$ & 1.896 & & \\
\hline$>10$ & & 1179 & 62.2 \\
\hline $1-10$ & & 695 & 36.6 \\
\hline$<1$ & & 22 & 1.2 \\
\hline $\begin{array}{l}\text { Chagas disease in another } \\
\text { family member }\end{array}$ & 1.947 & & \\
\hline Yes & & 1384 & 71.1 \\
\hline No & & 384 & 19.7 \\
\hline Do not know & & 179 & 9.2 \\
\hline $\begin{array}{l}\text { Previous treatment for Chagas } \\
\text { disease }\end{array}$ & 1.953 & & \\
\hline Yes & & 1008 & 51.6 \\
\hline No & & 873 & 44.7 \\
\hline Do not know & & 72 & 3.7 \\
\hline $\begin{array}{l}\text { Previous use of benznidazole } \\
\text { medicine }\end{array}$ & 1.955 & & \\
\hline No & & 1320 & 67.5 \\
\hline Yes & & 492 & 25.2 \\
\hline Do not know & & 143 & 7.3 \\
\hline NYHA Functional Classification & 1.931 & & \\
\hline 1 & & 1059 & 54.8 \\
\hline II or more & & 872 & 45.2 \\
\hline NT-ProBNP level, pg/mL & 1.955 & & \\
\hline$<300$ & & 1368 & 70.2 \\
\hline$\geq 300$ & & 581 & 29.8 \\
\hline
\end{tabular}

access to healthcare of Chagas disease patients in the coming years.

Second, the SaMi-Trop cohort represents a major challenge for focused research in neglected diseases, with knowledge that can be applied in primary healthcare. The study has the potential to provide relevant information about the development and progression of Chagas disease in remote areas with social and economic inequalities. As pointed out by Maguire, ${ }^{31}$ there is an urgent need for a new strategy for Chagas disease treatment and studies for evaluation of results because the infected patients are ageing and have only a few years left to live.

One weakness of the study is that no data on weight and height in the health services indicators were included at the baseline. Another important limitation is the lack of baseline echocardiograms, which could help in the clinical stratification of patients. All this information is being collected in the second follow-up visit. As the focus was to find biomarkers related to the cardiac outcome and given the budgetary limitations, no 
Table 5 Prevalence of comorbid conditions, selected behavioural characteristics, medications used, signs and symptoms, and self-reported health in the SaMi-Trop cohort.

\begin{tabular}{|c|c|c|c|}
\hline Variables & Valid N & $\mathbf{N}$ & Per cent \\
\hline Comorbid conditions & 1.959 & & \\
\hline High serum cholesterol & & 785 & 40.1 \\
\hline Hypertension & & 706 & 36.0 \\
\hline Diabetes mellitus & & 198 & 10.1 \\
\hline Thyroid disorder & & 159 & 8.1 \\
\hline Kidney disease & & 143 & 7.3 \\
\hline Leishmaniosis & & 22 & 1.2 \\
\hline Behavioural characteristics & 1.945 & & \\
\hline Physical activity last week (minimal $30 \mathrm{~min}$ ) & & 434 & 22.3 \\
\hline Alcohol last month & & 318 & 16.2 \\
\hline Current smoking & & 143 & 7.3 \\
\hline Number of medicine in use & 1.959 & & \\
\hline 0 & & 589 & 30.1 \\
\hline $1-2$ & & 714 & 36.4 \\
\hline $3-4$ & & 538 & 27.5 \\
\hline$\geq 5$ & & 118 & 6.0 \\
\hline Medicine in use (yes) & 1.940 & & \\
\hline Diuretics & & 951 & 49.1 \\
\hline ACE & & 553 & 28.6 \\
\hline ARBs & & 550 & 28.4 \\
\hline Aspirin & & 507 & 26.2 \\
\hline Amiodarone & & 429 & 22.0 \\
\hline Carvedilol & & 380 & 19.6 \\
\hline Digoxin & & 140 & 7.2 \\
\hline$\beta$-blockers & & 140 & 7.2 \\
\hline Vasodilators & & 84 & 4.3 \\
\hline Warfarin & & 11 & 0.6 \\
\hline Signs and symptoms or self-reported conditions (yes) & 1.924 & & \\
\hline Heartbeat racing or beating abnormally & & 1.222 & 63.5 \\
\hline Prolonged faintness or dizziness & & 1.203 & 62.5 \\
\hline Problems on ECG & & 1.180 & 61.3 \\
\hline Heart palpitations & & 1.174 & 61.0 \\
\hline Short of breath during physical exercises & & 1.143 & 59.4 \\
\hline Heartbeat racing at rest & & 1.015 & 52.8 \\
\hline Heartbeat not regular & & 902 & 46.9 \\
\hline Difficulty breathing when lying down & & 752 & 39.1 \\
\hline Unable to climb two flights of stairs & & 749 & 38.9 \\
\hline Awake during the night unable to breath & & 683 & 35.5 \\
\hline Trouble swallowing & & 599 & 31.1 \\
\hline Swelling or puffiness of the feet in the morning & & 502 & 26.1 \\
\hline No bowel movement for three or more days & & 478 & 24.8 \\
\hline Fainting or loss of consciousness & & 429 & 22.0 \\
\hline Visible neck veins when standing up or sitting & & 409 & 21.3 \\
\hline Pain when swallowing food & & 342 & 17.8 \\
\hline Pacemaker & & 110 & 6.2 \\
\hline Megaesophagus & & 117 & 6.1 \\
\hline
\end{tabular}

indeterminate form or negative controls were included in this cohort; this will preclude the study of the early biomarkers of disease progression. However, Chagas disease is mostly a disease of adults and older age groups in countries where the vectorial transmission was interrupted and this cohort provides a unique opportunity for recognising predictors of higher risk using simple biomarkers in a community sample of patients with Chagas cardiomyopathy.

\section{COLLABORATIONS}

Collaborations in data analysis will be welcome through specific research proposals sent to individual SaMi-Trop investigators. Exchange of doctoral or postdoctoral fellows is very welcome.

The data set will be open access for two years at the end of the data collection process (August 2018). In the meantime, applications to use the data should be made by contacting the researchers of the SaMi-Trop cohort 
and filling in the application form. The questionnaires and interviewer guides of the baseline will also be available in electronic formats at http://www.ufsj.edu.br/ tecnologiasemsaude_pesquisa/projetos.php.

\section{Author affiliations}

${ }^{1}$ Federal University of São João del-Rei, Brazil

${ }^{2}$ University of California, Berkeley, California, USA

${ }^{3}$ Department of Infectious Diseases, School of Medicine and Institute of Tropical Medicine, University of São Paulo, São Paulo, Brazil ${ }^{4}$ Laboratory of Medicine Laboratorial (LIM03), General Hospital, School of Medicine, University of São Paulo, São Paulo, Brazil

${ }^{5}$ Health Science Programme, State University of Montes Claros, Montes Claros, Minas Gerais, Brazil

${ }^{6}$ Laboratory of Immunology, Heart Institute (InCor), School of Medicine, University of São Paulo, São Paulo, Brazil

${ }^{7}$ Division of Clinical Immunology and Allergy, School of Medicine, University of São Paulo, São Paulo, Brazil

${ }^{8}$ Institute for Investigation in Immunology, iii-INCT, São Paulo, Brazil

${ }^{9}$ Institute of Mathematics and Statistics (IME), University of São Paulo, São Paulo, Brazil

${ }^{10}$ Department of Internal Medicine, Universidade Federal de Minas Gerais, Belo Horizonte, Brazil

Acknowledgements The authors would like to thank all SaMi-Trop patients and health team in each municipality for their valuable contribution to this study.

Contributors CCS, ECS, CDO, ALPR were responsible for study concept, analyzed and interpreted the data, drafted and revised the manuscript, and approved the final version. LCO, AMF, EC-N, ALB, JEF, DSH, ALR to have substantially contributed to drafting the article or revising it critically for important intellectual content; and have given the final approval of the version to be published.

Funding The SaMi-Trop cohort study is supported by the National Institutes of Health (NIH), (P50 Al098461-02), Brazilian National Research Council, CNPq (467043/2014-0) and the State Funding Agency of Minas Gerais, FAPEMIG (REDE 018-14). ECS and ALPR are recipients of a research scholarship from CNPq and CCS of a postdoctoral scholarship from CAPES Foundation, Ministry of Education Brazil (BEX 2477/15-7).

Competing interests None declared.

Patient consent Obtained.

Ethics approval The SaMi-Trop Cohort was approved by the Institutional Review Board, number 179.685/2012 (National Commission of Ethics in Research, CONEP)

Provenance and peer review Not commissioned; externally peer reviewed.

Data sharing statement The SaMi-Trop data set will be open access for 2 years at the end of the data collection process (August 2018). In the meantime, applications to use the data should be made by contacting the researchers of the SaMi-Trop cohort and filling in the application form. The questionnaires and interviewer guides of the baseline will also be available in electronic formats at http://www.ufsj.edu.br/tecnologiasemsaude_pesquisa/ projetos.php; the SaMi-Trop is also registered in ClinicalTrail.gov: https:// www.clinicaltrials.gov/ct2/show/NCT02646943?term=SAMI-Trop\&rank=1.

Open Access This is an Open Access article distributed in accordance with the terms of the Creative Commons Attribution (CC BY 4.0) license, which permits others to distribute, remix, adapt and build upon this work, for commercial use, provided the original work is properly cited. See: http:// creativecommons.org/licenses/by/4.0/

\section{REFERENCES}

1. Bern C. Chagas' disease. N Engl J Med 2015;373:456-66

2. Marin-Neto JA, Cunha-Neto E, Maciel BC, et al. Pathogenesis of chronic Chagas heart disease. Circulation 2007;115:1109-23.
3. Laranja FS, Dias E, Nobrega G, et al. Chagas' disease: a clinical, epidemiologic, and pathologic study. Circulation 1956;14:1035-60.

4. Sabino EC, Ribeiro AL, Salemi VM, et al, National Heart, Lung, and Blood Institute Retrovirus Epidemiology Donor Study-II (REDS-II), International Component. Ten-year incidence of Chagas cardiomyopathy among asymptomatic Trypanosoma cruzi-seropositive former blood donors. Circulation 2013;127:1105-15.

5. Nunes MC, Dones W, Morillo CA, et al., Council on Chagas Disease of the Interamerican Society of Cardiology. Chagas disease: an overview of clinical and epidemiological aspects. J Am Coll Cardiol 2013;62:767-76.

6. Rocha MO, Teixeira MM, Ribeiro AL. An update on the management of Chagas cardiomyopathy. Expert Rev Anti Infect Ther 2007;5:727-43.

7. MS-Ministério da Saúde. Consenso brasileiro em doença de Chagas. Rev Soc Bras Med Trop 2005;38:1-29.

8. Rocha MO, Ribeiro AL, Teixeira MM. Clinical management of chronic Chagas cardiomyopathy. Front Biosci 2003:8:e44-54.

9. Lima-Costa MF, Peixoto SV, Ribeiro AL. Chagas disease and mortality in old age as an emerging issue: 10 year follow-up of the Bambuí population-based cohort study (Brazil). Int J Cardiol 2010;145:362-3.

10. Pereira Nunes MC, Barbosa MM, Ribeiro AL, et al. Predictors of mortality in patients with dilated cardiomyopathy: relevance of Chagas disease as an etiological factor. Rev Esp Cardiol 2010;63:788-97.

11. Rassi A Jr, Rassi A, Little WC, et al. Development and validation of a risk score for predicting death in Chagas' heart disease. $N$ Engl $J$ Med 2006;355:799-808.

12. Ribeiro AL, Cavalvanti PS, Lombardi F, et al. Prognostic value of signal-averaged electrocardiogram in Chagas disease. J Cardiovasc Electrophysiol 2008;19:502-9.

13. Benchimol-Barbosa PR, Tura BR, Barbosa EC, et al. Utility of a novel risk score for prediction of ventricular tachycardia and cardiac death in chronic Chagas disease-the SEARCH-RIO study. Braz J Med Biol Res 2013;46:974-84.

14. Bautista-López NL, Morillo CA, López-Jaramillo $\mathrm{P}$, et al. Matrix metalloproteinases 2 and 9 as diagnostic markers in the progression to Chagas cardiomyopathy. Am Heart J 2013;165:558-66.

15. Ferreira LR, Frade AF, Santos RH, et al. MicroRNAs miR-1, miR-133a, miR-133b, miR-208a and miR-208b are dysregulated in Chronic Chagas disease cardiomyopathy. Int $J$ Cardiol 2014;175:409-17.

16. Alkmim MB, Figueira RM, Marcolino MS, et al. Improving patient access to specialized health care: the Telehealth Network of Minas Gerais, Brazil. Bull World Health Organ 2012;90:373-8.

17. Ribeiro ALP, Marcolino MS, Prineas RJ, et al. Electrocardiographic abnormalities in elderly Chagas disease patients: 10-year follow-up of the Bambuí Cohort Study of Aging. J Am Heart Assoc 2014;3:e000632.

18. Peduzzi $\mathrm{P}$, Concato J, Feinstein AR, et al. Importance of events per independent variable in proportional hazards regression analysis II. Accuracy and precision of regression estimates. J Clin Epidemiol 1995:48:1503-10.

19. Goldman L, Hashimoto B, Cook EF, et al. Comparative reproducibility and validity of systems for assessing cardiovascular functional class: advantages of a new specific activity scale. Circulation 1981;64:1227-34.

20. Fleck MPA, Louzada S, Xavier M, et al. Aplicação da versão em português do instrumento abreviado de avaliação da qualidade de vida "WHOQOL-bref". Rev Saude Publica 2000;34:178-83.

21. Apolinario D, Braga RCOP, Magaldi RM, et al. Short Assessment of Health Literacy for Portuguese-speaking Adults. Rev Saude Publica 2012;46:702-11.

22. Macfarlane PW, Latif S. Automated serial ECG comparison based on the Minnesota code. J Electrocardiol 1996;(29 Suppl):29-34.

23. Ribeiro AL, dos Reis AM, Barros MV, et al. Brain natriuretic peptide and left ventricular dysfunction in Chagas' disease. Lancet 2002;360:461-2.

24. Lima-Costa MF, Cesar CC, Peixoto SV, et al. Plasma B-type natriuretic peptide as a predictor of mortality in community-dwelling older adults with Chagas disease: 10-year follow-up of the Bambui Cohort Study of Aging. Am J Epidemiol 2010;172:190-6.

25. Morillo CA, Marin-Neto JA, Avezum A, et al. Randomized trial of benznidazole for chronic Chagas' cardiomyopathy. N Engl J Med 2015;373:1295-306.

26. Mond HG, Proclemer A. The 11th world survey of cardiac pacing and implantable cardioverter-defibrillators: calendar year 2009-a World Society of Arrhythmia's project. Pacing Clin Electrophysiol 2011;34:1013-27. 
27. Kirchhoff LV. Chagas disease (American trypanosomiasis): background, pathophysiology, epidemiology. Medscape reference. Drugs, Diseases \& procedures 2014. http://emedicine.medscape. com/article/214581-overview\#a6

28. Matos CS, Santos JJE, Medeiros FAC, et al. Current situation and perspectives regarding human Chagas disease in midwestern of the state of Minas Gerais, Brazil. Mem Inst Oswaldo Cruz 2014;109:374-8.
29. Marcolino MS, Palhares DM, Ferreira LR, et al. Electrocardiogram and Chagas disease: a large population database of primary care patients. Glob Heart 2015;10:167-72.

30. Travassos $C$, Viacava F, Pinheiro R, et al. Utilização dos serviços de saúde no Brasil: gênero, características familiares e condição social. Rev Panam Salud Publica 2002;11:365-73.

31. Maguire JH. Treatment of Chagas' Disease-time is running out. N Engl J Med 2015;373:1369-70. 